\title{
LA VERACIDAD-SINCERIDAD SEGÚN LEONARDO POLO
}

\author{
Veracity-Truthfulness according to Leonardo Polo
}

\author{
Juan Fernando Sellés ${ }^{\mathrm{I}}$
}

\section{Resumen}

En este trabajo se estudia la virtud de la veracidad-sinceridad según el pensamiento de Leonardo Polo. En primer lugar, se describe su índole y sus tipos -lingüística y laboral-. En segundo lugar, se revisan los vicios contrarios a ella -error, mentira, silencio injustificado y doblez-. En tercer lugar, se indican algunas ventajas de su adquisición -alegría, audacia, incremento del bien común y enamoramiento de la verdad-. Se propone a estudio este tema porque la mentira, bajo sus diversas formas, es un grave problema en nuestra sociedad, la cual, además de ser expansiva es disolvente del lenguaje y de la sociedad. Los objetivos principales de este trabajo consisten en revisar todos los textos pertinentes de L. Polo - uno de los pensadores más prominentes de nuestros días- sobre la virtud de la veracidad, su vicio opuesto, la mentira, y las consecuencias inherentes a dicha virtud. El marco conceptual de este trabajo es del ámbito de la ética, la cual es segunda respecto de la antropología trascendental o de la intimidad, ya que si se acepta la distinción real tomista entre actus essendi-essentia, la ética es manifestación del acto de ser personal humano en la esencia del hombre, susceptible de perfeccionarla o envilecerla. La metodología empleada es teórica, porque según la sentencia aristotélica 'la teoría es la forma más alta de vida’; por tanto, para alcanzar la intimidad humana el único método válido es que el propio existente se ponga enteramente en juego y advierta cuál es la raíz de la veracidad, bien de sus manifestaciones virtuosas, bien de las viciosas. La conclusión principal a la que se llega es que la raíz de la falta de veracidad, la mentira, es la despersonalización o pérdida progresiva del acto de ser personal humano, merma que provoca en la esencia del hombre la progresiva deshumanización. Dicho esto, se ve claramente que las implicaciones que esto comporta, frente a nuestra sociedad, son su sujeción a un permanente estado de crisis.

Palabras clave: Virtud; Veracidad; Sinceridad; Leonardo Polo; Vicios contrarios; Error; Mentira; Silencio injustificado; Doblez.

1 Doctor en Filosofía y Profesor Titular de Antropología en la Universidad de Navarra, Espańa. jfselles@unav.es 


\section{Abstract}

The article addresses the virtue of veracity-truthfulness in the thought of Leonardo Polo. First, it describes its nature and types (linguistic and labor). Second, it reviews the bad habits that are contrary to this virtue: error, lie, unjustified silence and duplicity. Third, it shows some advantages that come with having it: happiness, audacity, increase of common good and love for truth. This topic is discussed because lie, in all the possible manifestations, is a major issue the contemporary society, which not only is increasing, but also disrupts the language and community. Therefore, the purpose of the research is to review every pertinent work by Leonardo Polo regarding both the virtue of truthfulness and its contrary bad habit, lie; and, also, the consequences that come with this virtue. The research is framed within ethics, which is second to transcendental anthropology, because if the Thomist distinction between actus essendi and essentia is accepted, ethics becomes the manifestation of the act of being of humans within the essence of humans, which can perfect or degrade such essence. The research follows a theoretical method because according to Aristotle "the life according to reason is best and pleasantest"; thus, the only truth method would be for the being to put everything on the line and find out what is the cause of truthfulness, and of its virtuous and vicious manifestations. It concludes that the cause of the lack of truthfulness, lie, is the depersonalization or progressive loss of the act of being human. Bearing this on mind, for our society this involves being in a permanent state of crisis.

Keywords: Virtue; Veracity; Truthfulness; Leonardo Polo; Bad Habits; Error; Lie; Unjustified Silence; Duplicity.

\section{Planteamiento}

Antes de abordar esta virtud de dos nombres según el pensamiento de Leonardo Polo, se pueden tener en cuenta algunos ejemplos que él aduce, los cuales, por ser él filósofo, hacen referencia a célebres personajes de la historia del pensamiento. Pone como ejemplo de sinceridad a Platón, porque este no solo dice lo que ha descubierto, sino que también confiesa lo que no sabe, sobre todo en su época de vejez, su fase autocrítica ${ }^{2}$. Otro ejemplo que aduce es el de Kierkegaard, al que califica de 'cristiano sincero' (Polo, 2018, p. 52$)^{3}$, porque este autor, al notar la sublimidad de la doctrina cristiana, no solo decía que en su época y país ya no quedaban cristianos, sino que él mismo dejaba mucho que desear como auténtico cristiano.

Por otra parte, Polo tilda de insinceridad la conversión interesada de la familia de Marx al protestantismo, lo cual repercutió netamente en la vida de este pensador: "el cambio de religión tan insincero que su familia llevó a cabo le sugirió que la religión es secundaria y está determinada por intereses más importantes, que son socioeconómicos" (Polo, 2018, p. 80). Como ejemplo político de falta de transparencia, Polo aludió

2 "Platón es un pensador muy sincero, fiel a la verdad, de amplias miras, como prueba su propuesta de visión global. No disimula sus errores cuando los percibe, ni se conforma con soluciones aparentes, con componendas". (Polo, 2015, p.77). En otro lugar añade: "la honradez intelectual de Platón se nota en que se autocritica". (2015, p. 211).

3 En efecto, el gran danés escribió: "Siempre he considerado como cosa esencial la sinceridad”. (Kierkegaard, 1982, p. 51). También para Jaspers, la máxima exigencia de Kierkegaard era la sinceridad. (Jaspers, 2005, p. 52). 
a muchos países latinoamericanos, a la vieja URSS y sus naciones satélites y, también, a la Comunidad Europea. A ellos se podría sumar, sin forzar los acontecimientos, la falta de veracidad en buena parte de los políticos actuales.

¿Qué indica lo precedente? En cuanto a los filósofos, que solo lo son, en rigor, los que aman la verdad por encima de sus intereses, pues, como diría Polo (2018): "la filosofía es el amor a la verdad, la búsqueda de la verdad. La filosofía se ocupa de la verdad de modo global, sin restricciones. Lleva consigo una actitud sin la cual el amor a la verdad no aparecería, o estaría condicionado por otros intereses; el amor a la verdad tiene que ser sincero, auténtico" (Polo, 2015, p. 27). En cuanto a las demás personas, lo que precede indica que quienes no son sinceros se engañan a sí mismos. Es decir, que son ellos los más perjudicados, ya que "el hombre se engaña porque no quiere ser sincero y no profundiza; es decir, porque se oculta a sí mismo los móviles auténticos de su actitud" (Polo, 2015b, p. 150).

\section{La veracidad y sus tipos}

Para Tomás de Aquino la veracidad era una virtud de la voluntad ${ }^{4}$. En cambio, para Polo, es una virtud de la razón" ‘. Como la razón es una potencia inmaterial dirige lo que es sensible en nosotros; en primer lugar, el lenguaje, que es la primera praxis transitiva; y en segundo lugar, y en correlación con ella, las demás acciones transitivas humanas, en especial el trabajo de transformación. En cuanto a la primera praxis, Polo pregunta: "¿Se puede usar el lenguaje de cualquier manera? No, sino que el lenguaje hay que emplearlo según una norma: la veracidad. El que no usa su lenguaje verazmente está destruyendo su lenguaje. Destruir el lenguaje es hacer imposible la cooperación humana, y por tanto estorbar el desarrollo y la organización del trabajo humano" (Polo, 2015, p. 165). La falta de cooperación humana imposibilita el trabajo de transformación y estropea los bienes mediales, pues los productos culturales no comparecen en el ámbito social. Además, imposibilita un bien más alto, las virtudes; como estas son superiores a los bienes materiales, cabe decir que la falta de veracidad inhibe el bien común. A continuación distinguiremos, según Polo, entre los dos tipos de veracidad:

a) Veracidad lingüistica. Por una parte, la veracidad es la virtud que dirige el modo de hablar. No se debe hablar de cualquier modo sino según la veracidad, porque la mentira inutiliza el lenguaje. En cambio, la veracidad favorece la comunicación, y esta, la convivencia. La veracidad no es la única virtud que le favorece, pero es indispensable para el diálogo: "hábitos muy importantes, como la veracidad, la confianza mutua y la amistad están vinculados a la comunicación” (Polo, 2015,p. 377). Sin comunicación oral y escrita las personas humanas no se pueden vincular entre sí, y sin vinculación no pueden crecer según

4 "La verdad en cuanto que conocida pertenece al entendimiento. Pero el hombre, utilizando por propia voluntad sus facultades y miembros, se sirve de signos exteriores para manifestar la verdad, y así la manifestación de la verdad es acto de la voluntad". (Tomás de Aquino, II-II, q. 109, a. 1, ad 2.

5 "La prudencia atenderá este consejo (atenerse a la razón para atajar de algún modo los malos deseos), si está precedida por otra virtud dianoética que es la sinceridad”. (Polo, 2015, p. 514). 
virtud. La veracidad es indispensable para el diálogo ${ }^{6}$, pero también para la justicia y la amistad, virtudes centrales de la voluntad ${ }^{7}$.

Quienes estén obcecados en los bienes naturales o culturales es difícil que se den cuenta de la pérdida de la virtud. Para Polo esta ignorancia es típica de los que denomina 'hombres masa'. De aquí que afirme que "el hombre masificado no admite la comunicación enriquecedora. Por eso, bastantes de los llamados medios de información han perdido el auténtico sentido del lenguaje. La eticidad del lenguaje consiste en la relación recíproca entre los hablantes. Aquí se asienta el deber y la virtud de la veracidad" (Polo 2018, p. 308). A nadie se le oculta la pobreza del lenguaje de los actuales representantes políticos nacionales e internacionales, de los informativos, de las películas, en general, de los medios de comunicación; asimismo, de quienes ejercen profesiones liberales, de los alumnos universitarios y, desde luego, de la gente, por así decir, de a pie; tal lenguaje no pocas veces es rastrero, soez, inhumano, despersonalizante; otras, calumnioso y mendaz. Y como el lenguaje oral es la primera manifestación sensible humana, es el elemento en el que primero se muestra la gran crisis por la que atraviesa la humanidad. En cuanto al lenguaje escrito, es claro que hoy se publica más que en tiempos pasados, tal vez escritos mejor presentados formalmente que antaño, pero suelen ser de menor calidad en contenido. Respecto de esto Polo decía que, por carecer de descubrimientos, muchos libros y artículos no deberían publicarse.

La sociedad actual se está diluyendo porque sus bases vinculantes son, por este orden de superior a inferior, la familia, la universidad (es decir, la educación hasta su más alto nivel, el universitario) y la empresa ${ }^{8}$. Es claro que se miente en familia (de lo contrario esta no se escindiría), entre los colegas universitarios (de lo contrario la interdisciplinariedad no sería un grave problema), y asimismo en la empresa (pues en caso contrario no habría recesión económica, desempleo, contratos basura, etc.). Ante este generalizado panorama conviene declarar que, pese a las apariencias, la mentira no libera, sino que esclaviza. La sentencia evangélica 'la verdad os hará libres' no debe tomarse solo como un asunto de fe sobrenatural, sino también naturalmente. Ni la familia la forma una sola persona, así como la educación yel trabajo solo son posibles en común. Ahora bien, ninguna de estas bases sociales está viva y prospera sin veracidad.

Para Polo la veracidad es superior a las virtudes tenidas como centrales por la ética clásica, a saber, las cuatro llamadas cardinales, porque sin la veracidad aquellas no lo son: "Es imprescindible esta breve alusión a las virtudes cardinales, las virtudes quicio, de que habla la ética clásica: prudencia, justicia, fortaleza, templanza. Pero hay más: la veracidad, la amistad, la más importante de las virtudes según Aristóteles. La amistad exige respeto, estima mutua. ¿Qué amistad puede haber sin diálogo?” (Polo 2018, p. 312-313), ¿y qué diálogo sin veracidad? Nótese que esta superioridad no se da solo sobre las virtudes de la voluntad,

6 Como es sabido, el miedo reinante en la antigua URSS inhibía la veracidad. De tal actitud se han hecho eco muchos literatos. Así, en un libro de uno de ellos se lee: “¡Oh, maravillosa y clara fuerza del diálogo sincero, fuerza de la verdad! ¿Qué precio tan terrible han tenido que pagar a veces los hombres por decir algunas palabras valientes, sin guardarse las espaldas!". (Grossman 2007, p. 363).

7 "La sinceridad es hablar sin rodeos y con confianza, así como disentir sin hipocresía y abrir libremente el propio interior: esto se llama franqueza. La generosidad lleva consigo el no reparar en los pequeños defectos que todos tenemos, y conduce a conceder un amplio crédito al amigo". (Polo, 2015.p. 475).

8 Cfr. al respecto ver: Sellés, 2013. 
sino también respecto de la virtud de la razón práctica considerada superior por los clásicos, la prudencia, la cual, según ellos, es auriga y genitrix virtutum.

En efecto, tras el saber deliberar (eubulia), tras la sensatez del juicio práctico (synesis) -incluso en casos excepcionales (gnome)-, la razón práctica culmina con el saber imperar o mandar cuando y como es debido (prudencia) ${ }^{9}$. Pero, por encima de este hábito de la razón práctica está la veracidad, que consiste en transmitir a los demás los aciertos prudenciales obtenidos y puestos por obra, para que también los demás aprendan, pues así incrementa más el bien común. Asimismo, se podría pensar que la veracidad es una parte de la justicia, dado que esta se entiende como 'dar a cada uno lo suyo', por tanto, también con las palabras. Pero Polo sostiene que "la virtud de la veracidad es más que una parte potencial de la justicia, pues sin comunicación la sociedad humana es imposible, y la veracidad es la clave de la comunicación" (Polo 2015, p. 468). En cuanto a la amistad, Polo ve que no es ajena a esta virtud: "también la veracidad es una dimensión de la amistad" (Polo 2015, p. 475), porque no cabe amistad sin verdad ${ }^{10} \mathrm{y}$, como es sabido, la amistad es superior a la justicia.

Con lo dicho, que parece poco pero que implica mucho, se nota hasta qué punto son deficientes las propuestas sociológicas habidas en el s. XX acerca del vínculo suficiente de cohesión social, pues ninguna de ellas pone el acento en esta virtud (en rigor, en la ética), y la más célebre y reciente de ellas la conculca abiertamente: "Habermas sostiene que nadie está obligado a declarar lo que vaya contra sus propios intereses; al someter la veracidad del diálogo a esa condición, se le desvirtúa" (Polo 2015, p. 376). La verdad no se puede subordinar a ninguna utilidad, porque la verdad no tiene sustituto útil, ya que es valiosa en sí.

Que esta moderna tesis es contraria a la clásica, en concreto a la tomista, patet. Dice Polo (2019):

La veracidad es una de las dimensiones de la sociabilidad humana que hoy menos claras están: no se percibe hasta qué punto la coordinación de esfuerzos es incompatible con la mentira. Tomás de Aquino declara de modo muy neto, al hablar de las virtudes básicas de la sociabilidad, que sin veracidad la sociedad es imposible, porque su gran conectivo es el diálogo, la comunicación, y si se atenta contra la verdad, se produce la incomunicación, y la sociedad se pulveriza. Una sociedad de personas que no viven la veracidad, que prescinden de la comunicación como conectivo social, no puede funcionar, se desmorona. Pero hoy no lo vemos con tanta claridad (p. 361; Cf. Aquino, p. 109).

Porque nuestra sociedad no se juega la vida por la verdad, y en consecuencia, ésta ni le respalda ni le inspira, es decir, no permea de sentido la vida.

b) Veracidad laboral. Por otra parte, la veracidad debe dirigir todas nuestras acciones, entre las que predominan las laborales. Polo (2019) pregunta: “¿Cómo hacer ver hasta qué punto la comunicación es imprescindible? ¿Cómo percatarnos de que es signo de la salud de una institución el trabajo en equipo? Piénsese en el grave error que implicaría, por ejemplo, que el jefe de un departamento de medicina, no quisiera decir todo lo que sabe a sus colaboradores por miedo a que éstos se hagan mejores que él. Hay personas que se reservan información porque quieren mantener una situación de privilegio. Pero si se

9 Cfr. al respecto de Polo 2015, pp. 459-464. Cfr asimismo: Sellés, 1999; 2008, pp. 325-413.

10 Cfr. sobre este punto, Sallés2012, pp. 9-14. 
procede de esa manera, la institución está perdida; institucionalmente, que un individuo tenga éxito y los otros no, es peor a que cualquiera de ellos pueda tenerlo; quien no lo vea así, está enquistado en ella, se autoexcluye o niega a los otros la condición de miembros" (Polo, 2019, p. 366). El hombre está hecho para trabajar y caben dos tipos de trabajos: uno superior, el de relación interpersonal cuyo conectivo es el lenguaje, y otro inferior, de transformación de la realidad física, cuyo conectivo son las diversas técnicas instrumentales que transforman la realidad física en productos culturales.

Quien no habla se desvincula socialmente y quien no trabaja también. En cuanto a lo primero, "se debe sentar con energía un principio universal: en principio es mejor hablar que callarse... Contribuye más a la vida social, siempre que no sea hablar de trivialidades o chismorrerías. Aporta más al hombre hablar que el silencio. Como es claro, callarse es necesario para escuchar. El diálogo se compone de enunciados, respuestas y escuchas. Más todavía: el hombre está hecho para comunicarse, no para denegar la comunicación. Existe una obligación moral, derivada del destino del hombre a la verdad, a no reservarse lo que se sabe, al que corresponde un derecho a ser escuchado. Asimismo, reservarse la capacidad de escuchar, o limitarla a unos pocos es un prejuicio individualista o elitista del que conviene librarse" ${ }^{11}$. Por otra parte, si el hombre está hecho para trabajar y no trabaja, miente como hombre. Se puede no trabajar nada, o también trabajar sin cumplir lo requerido. En el primer caso estamos ante la mentira radical. En el segundo, ante el incumplimiento de lo pactado:

Los reglamentos son necesarios para prevenir conductas irresponsables. La doblez práctica es la peor forma de mentira. La justificación consecuencialista de la mentira no parece aplicable a la doblez. Otras formas de mentir se castigan de acuerdo con sus resultados; en cambio, dejar de hacer lo pactado se ha de prevenir con reglamentos, porque destruye la organización del trabajo: sin integridad no hay valor añadido. Quien desiste, el inconstante que cambia su conducta por motivos fútiles, la persona caprichosa, no produce ni mejora. La lealtad a la palabra mide la capacidad de compromiso, de acuerdo con el cual la acción es imperada y dirigida a fines. Por eso es preciso saber qué compromisos se contraen, pues los adquiridos se han de cumplir (salvo inmoralidad intrínseca de los mismos). Incluso el perezoso ha de avisar para no ser traidor. (Polo, 2019, p. 392). ${ }^{12}$

\section{Los defectos contra la veracidad}

"El siguiente paso es considerar en qué defectos incurre el hombre, de manera que su veracidad se deteriore. Según los clásicos, hay cuatro defectos que se oponen a la veracidad: en primer lugar, el error; en segundo lugar, lo que más directamente ataca a la verdad es la mentira (la locutio contra mentem); también el silencio,

11 El texto sigue así: "En principio es mejor hablar: pero de asuntos serios. Hay cosas concretas de las que no se debe hablar por secreto natural o de oficio, y otras insignificantes de las que no merece la pena ocuparse; en tal caso lo mejor es cortar para evitar perder el tiempo. Las excepciones al deber de hablar son numerosas, pero siempre particulares". (Polo, 2019, pp. 364-365).

12 Dicho con un ejemplo poliano: “¿Qué pasa cuando una piedra es llevada entre dos, y uno no cumple su cometido, sino que descarga el peso en el otro? Es obvio que ese otro no querrá seguir trabajando con el falsificador de la colaboración”. (Polo, 2019, p. 393). 
que en principio no está justificado por ser una excepción a la comunicación, a ese salir de sí que es hablar, un requisito propio del plexo social (el silencio, por tanto, sólo se justifica in casu); por último, también va contra la verdad la duplicidad (por así decirlo, la mentira existencial); la duplicidad no es pensar una cosa y decir otra, sino el no cumplir la palabra dada, la falta de veracidad en el orden de la acción práctica, el decir que sí y no hacer, anunciar un modo de conducta y actuar de otra manera. Este es el defecto más a la vista, y por ello el que más estropea el cuerpo social” (Polo, 2019, p. 370). La expresión poliana 'según los clásicos' significa 'según Tomás de Aquino'13.

Los remedios que Polo propone contra estos vicios son los siguientes: "Frente al error, lo correcto es lo que podríamos llamar la objetividad, el no emitir juicios precipitados o infundados. Directamente, contra la mentira, hay que decir la verdad. Frente al silencio, la sinceridad; el hombre sincero es el que no disimula eludiendo lo esencial. Por último, contra la doblez, contra el no cumplir la palabra dada, está la integridad, la lealtad a los demás y a mí mismo" (Polo, 2019, p. 361). Detengámonos en la descripción de dichos errores.

a) Error. Si la veracidad es intelectual, afirma Polo (2015): "ha de tenerse siempre en cuenta que el error es un acto formalmente voluntario y no intelectual" (p.119); en consecuencia, que "el error es error por su intensidad voluntaria” (p.122), y más o menos error según sea dicha intensidad. El error es afirmar como verdadero aquello de lo que se desconoce su verdad. Eso no puede ser racional porque lo propio de la razón es conocer, en cada acto, lo propio suyo; por tanto, tiene que ser voluntario: "el error no es lo contrario de la afirmación, sino una afirmación sobre la nada. Al error es inducida la voluntad” (p.123). El conocer humano conoce su tema propio en la medida del acto de conocer que ejerce. Sus actos pueden ser más o menos actos, pero que lo sean menos no equivale a decir que se equivoquen al conocer: "La imperfección del conocimiento, empero, no es suficiente para producir el error; este exige la intervención de la voluntad" (p.124)

Ahora bien, la voluntad ni se pronuncia sobre un juicio racional ni corta la deliberación de la razón sin la anuencia de la persona que está queriendo. Por eso, afirma Polo ( 2015): "la causa del error... es la sustitución del axioma A (el conocimiento es acto) por el sujeto" (Polo, 2015, p. 38) ) $^{14}$. El conocer humano no es, claramente, absoluto, pero posee una dimensión absoluta, a saber, que conoce como conoce -en la medida del acto que ejerce- y no puede conocer de otro modo. Pero pretender que conozca de otro modo, o que lo conocido sea distinto de como es conocido, no es propio del conocer, sino un deseo injustificado del querer humano en la medida en que este es respaldado por la persona. Por eso, siguiendo a Polo (2015), cabe decir que "el error es la pretensión de pensar un objeto con una operación que no le corresponde" (Polo, 2015, p. 244), siendo esa pretensión subjetiva. En este sentido, Polo dice que "los

13 "Hay que considerar los vicios opuestos a la verdad (aunque habría que decir más bien en este contexto la veracidad, porque todos esos vicios nacen de la voluntad). El primero es la mentira; el segundo, la simulación o hipocresía; el tercero, la jactancia y su vicio opuesto". (Aquino, II-II, qq. 110-113). En esas cuestiones trata de estos vicios: la mentira, la simulación, la hipocresía, la jactancia, afectación o presunción, y la ironía.

14 Esto significa que el sujeto se enfrenta a lo conocido por el conocer no aceptándolo porque sus preferencias son otras: "Otras causas de error son justamente las preferencias subjetivas. Cuando una persona tiñe la realidad con sus afectos no se equivoca porque su saber sea escaso, sino porque su mirada no es limpia. Por eso tiene sentido hablar de objetividad; un hombre objetivo pretende ante todo atenerse a la realidad y no traicionar su propio pensamiento". (Polo, 2019, p. 381). 
errores son conculcaciones del axioma de la conmensuración" (2019, p.459); es decir, a tanto acto de conocer corresponde tanto objeto conocido, ni más ni menos; y a la inversa: a tanto objeto conocido pertenece tanto acto de conocer, pues el acto de conocer no puede ser menos que lo conocido y lo conocido no puede ser menos que el acto de conocerlo.

Si el error no fuera voluntario, no se tendría como un vicio. Pero, para Polo (2018), los vicios intelectuales son fundamentalmente dos: la curiosidad y el error. La curiosidad se describe como el afán de conocer cosas que no merecen la pena ser conocidas. Por su parte, "el error es un vicio de la inteligencia que se define como el atreverse a afirmar lo que no se sabe" (p.227) ${ }^{15}$. Además, siguiendo a Tomás de Aquino ${ }^{16}$, Leonardo Polo escribe que "el error tiene razón de pecado, porque es consecuencia de la precipitación que lleva a afirmar lo que se ignora, lo cual es un pecado contra el pensamiento y contra la verdad. Para evitar el error hay que reconocer la complejidad de los asuntos" (Polo, 2015, p. 216) ${ }^{17}$. Los moralistas suelen distinguir entre 'pecado material' y 'pecado formal'. En el primer caso no está tan implicada la voluntad como en el segundo.

Una actitud subjetiva semejante contra la verdad objetiva conocida es someterla al criterio voluntario de certeza, actitud típica de la filosofía moderna ${ }^{18}$ (i.e. Descartes, Kant, etc.). Es decir, no aceptar ninguna verdad, como tal, hasta que se esté 'completamente seguro' de ella. Esta actitud pone en duda la verdad. Pero, en opinión de Polo (2015): "someter la verdad al criterio de certeza constituye un error. El error no es sino paralización de la verdad” (p. 137). En efecto, es claro que uno duda porque quiere; sigue dudando si quiere: y deja de dudar cuando y porque quiere; todo lo cual es injustificable racionalmente e indica que no es el conocer sino la voluntad la que lidera la duda. Por tanto, la certeza y la duda no sirven para describir la verdad, como pretenden ciertos bienintencionados autores ${ }^{19}$.

También, afirma Polo (2019):

El error implica ignorancia: se yerra porque se ignora. Pero el que ignora y dice que ignora no cae en el error. Una cosa es la ignorancia y otra el error... La ignorancia hay que tratarla en relación con el error, pero distinguiéndola de él, porque la ignorancia no siempre es viciosa: ignoramos mucho más de lo que sabemos. El error siempre es vicioso, porque es una falta de responsabilidad, una ligereza; como dice Tomás de Aquino, se debe a una audacia absurda (uno se atreve a hablar de lo que no sabe), que no respeta el

15 Dicho con otra expresión poliana: "el error en estricto sentido teórico es atreverse a enunciar un juicio sin tener conocimiento suficiente”.(2019, p. 375).

16 "El error tiene manifiestamente razón de pecado". (Aquino, Q.D. De malo, q. 3, a. 7 co).

17 En otra parte ańade: "el error se origina por no haber tenido en cuenta suficientes aspectos, es decir, por el reduccionismo inherente al método analítico". (2019, p. 372). Y más adelante: "el error es una consecuencia de la ignorancia y que consiste en atreverse a hablar de lo que se ignora. Los filósofos decimos que el error es un vicio intelectual debido a la precipitación”. (p. 377).

18 "Para un moderno, la verdad es certeza. Pero, entonces, se pierde la verdad, ante todo, porque de antemano duda del dato y somete a sospecha al dato. Lo único que busca es la veracidad del dato, pero la veracidad no es lo mismo que la verdad; se aspira a estar seguro, a un estado de ánimo. Pero la verdad no es un estado de ánimo”. (Polo, pp. 181-182).

19 Así, se ha escrito que "es veraz quien manifiesta en calidad de cierto lo que él tiene por cierto y quien expone en calidad de dudoso lo que él juzga dudoso”. (Millán-Puelles, 1997, p. 293). 
tiempo, la oportunidad del decir; el que se equivoca, por lo menos, se precipita. Precipitarse es un vicio contra nuestra mente (lo mismo que la curiosidad), un mal uso de nuestra inteligencia que atenta contra la índole misma de nuestra actividad cognoscitiva, antecede a una equivocación práctica. (p.371).

Con todo, y como es sabido, la ignorancia también puede ser culpable. A saber, cuando se ignora lo que -en la propia profesión o estado, por ejemplo-debería saberse porque se quiere ignorar, por el motivo subjetivo que sea, por comodidad, por evitarse responsabilidades, etc.

¿Cómo combatir el error? Estudiando con más atención los asuntos. Repárese en que muchas ciencias positivas pretenden eliminarlo procediendo según el método de completa experimentación, o sea, de probar todos los casos -es decir, por ensayo y error- pero si de entrada se estudiase más, se ahorraría mucho tiempo en pruebas. En cualquier caso, como dice Polo, "la disminución del error es el aprendizaje" (2019, pp. 378 - 384). Hay disciplinas en las que no cabe una 'verdad' rotunda -por así decir, al 100\%-, como son las actividades de dirección de empresas (la verdad sin vuelta de hoja solo se da en los saberes que versan sobre lo necesario -ciencias teóricas-, no en los que versan sobre lo contingente -prácticas ${ }^{20}$. Pero también es neto que se debe tender a aumentar el porcentaje de 'verosimilitud', de probabilidad en los saberes prácticos: "evitar el error es una tarea que no se debe abandonar; que el error acontezca no quiere decir que no se pueda ir eliminando, que no se pueda ir conquistando el ámbito de la verdad al alejar las fronteras de lo falso: cuanto más se alejen, mejor será la decisión. Lo primero es pensar las cosas de acuerdo con ellas mismas sin dejarse influir por el estado de ánimo" (Polo, 2019, 382). El estado de ánimo -positivo y fuerte- conviene que aparezca después de haber estudiado bastante un asunto y, en consecuencia, luego de haber descubierto más verdad sobre él, pues solo así se es fiel a lo real y se pone por obra, con fuerza, la verdad descubierta.

Por lo demás, para Polo: "no se descubre la entera significación del error hasta que no se va más allá de él. Desde luego, si un pensamiento está equivocado, hay siempre por medio factores psicomorales" (2015, p.17). Esto indica que, si bien el error es siempre un límite para el pensamiento, quien lo limita es la voluntad humana respaldada por el sujeto. Cabe decir que todo error en el conocer es por déficit de conocer, no por conocer demasiado ${ }^{21}$, porque la voluntad le corta, por propios intereses, las alas al conocer, pues el conocer está diseñado para crecer, para conocer más. En suma, el error es malo, no enteramente inocente, $\mathrm{y}$, además, es precedente de los actos malos que quiere positivamente la voluntad. El error no es simplemente banal o indiferente. ¿Se puede disculpar, en cierto modo? Sí, pero solo 'en cierto modo'. Con todo, "el error es más disculpable que la mentira; la mentira, la doblez, no es disculpable nunca" (Polo, 2015 , p. 207). Pero el error no es enteramente disculpable porque su raíz es personal, y como a este nivel el mal es la mentira, el error tiene su raíz en la mentira.

Junto a los errores que se suelen atribuir a la inteligencia, están los llamados 'errores morales o prácticos', de los cuales es más culpable la voluntad y el sujeto que inclina a esta facultad a querer lo que no está claro en las actuaciones. Dice Polo: "existe el error moral. Éste es integrante de la ética precisamente porque la

20 Cfr. sobre la distinción clásica entre ambas vías operativas de la razón: Sellés, 1999.

21 Polo dice, por ejemplo, que "la lógica de Hegel es un tremendo error; y es un error, como todos los errores, por defecto". (2015, p. 207). 
recta ratio es razón correctora... La recta ratio indica que el error moral no es una eventualidad. El error moral afecta directamente al sujeto, porque el que ha de corregirse es él mismo. Si se dirige donde no quiere (o no debe) aparece el error" 2018, p.19). ${ }^{22}$. El hombre se decide por un bien que no es verdaderamente bien, sino solo aparentemente, porque no ha centrado con suficiencia su razón en él. De los errores prácticos o morales se sale corrigiéndolos. En palabras de Polo: "el hombre alcanza un actuar correcto precisamente en forma de corrección” (2015, p. 356). Por eso es tan importante saber rectificar. Además, proferir con sinceridad la expresión '¡Lo siento; me he equivocado!' es una manifestación de humildad, la cual es personal, signo neto de que la persona quiere crecer por la senda de la verdad a la par que advierte cuán pernicioso es el error para ella y para las demás personas.

Razón práctica recta es razón correcta, corregida, la cual se corrige mediante la prudencia. Dada nuestra condición falible en la razón práctica, sobre todo por su vinculación a la voluntad, pues se pueden corregir admitiendo que uno se ha equivocado. Solo así, la persona respalda más a la razón práctica para que siga descubriendo más verosimilitud en los asuntos contingentes, es decir, en los que pueden ser de un modo u otro. Para Polo: "Ser veraz no se reduce a no decir mentiras. Ser veraz es estudiar los asuntos; ante todo, tratar de evitar el error porque, aunque el error, a diferencia de la mentira, no es voluntario, algún antecedente voluntario tiene, pues implica no haber tenido en cuenta por pereza o por irresponsabilidad, cosas que deberían haber sido consideradas" (2019, p. 376).

Sin embargo, no todos los errores tienen el mismo peso. En filosofía hay que dejar al descubierto los errores, los que han cometido los autores célebres del pensamiento, porque esos (materialismo, escepticismo, relativismo...) tienen muchas implicaciones en la vida de las personas. Para todos es manifiesto que, en la actualidad, los profesores de filosofía se detienen mucho en explicar a los grandes pensadores, y poco o nada en declarar, de modo patente, dónde están sus aciertos y sus errores, sobre todo porque esto último no es 'políticamente correcto' en nuestro tiempo. A lo sumo, dicen: 'me gusta más tal autor que otro, o tal periodo de tal pensador que tal otra etapa suya'. Con esto la que siempre sufre es la verdad. Pero también padece el docente y el discente; el primero, porque la verdad deja de respaldar su indagación y de encomendarle la tarea de incrementarla ${ }^{23}$; el segundo, porque es privado de la verdad a la que tiene derecho.

22 A esto añade: "el error práctico que más frecuentemente puede cometerse por parte de la voluntad se debe a que está débil, torcida. Débil y torcida se dicen respecto de la voluntad, no de la razón. Deseo es potencia, no acto, y esa potencia es la que puede malograrse. Se ve que tiene sentido hablar de errores prácticos. Un error práctico es un error que fundamentalmente y con frecuencia está en la voluntad, o es subsiguiente a la voluntad, que es el modo como puede estar en la inteligencia, es decir, como consecuencia de la decisión. El error práctico consiste en la elección inadecuada de un medio que no lleva al fin último". (p. 65).

23 "Kant lo decía de una manera muy fuerte. La ética de Kant es incompleta, pero en esto acertó: el que dice mentira atenta ante todo contra sí mismo porque se escinde, pierde su integridad, y acaba inhabilitándose para la verdad. Atentar contra la propia coherencia es incurrir en la confusión interior. Lo peor de la mentira es que introduce una fisura en la propia unidad; eso es malo ontológicamente, y por tanto, moralmente. Al final, el que miente pierde el sentido de la verdad. El hombre mentiroso se engaña a sí mismo porque apenas discierne lo que es verdadero de lo falso... El que miente debilita su propio sentido de la verdad, y entonces no sabe tratar con la realidad, porque es posible engañar a los demás, pero a la realidad no. Actúo bien si estoy de acuerdo con la realidad. En cambio, si debilito mi órgano veritativo (que es la inteligencia) estropeo mis relaciones con la realidad y pierdo la capacidad de dirigirme o de dirigir a otros. Uno mismo no es inmune a la mentira, que se mete dentro del mentiroso; Kant lo ve y lo enuncia de un modo cercano a Sócrates". (Polo, 2019, p. 370). 
b) Mentira. Esta es peor que el error (Polo, 2019, p. 385), porque "la mentira es intrínsecamente mala" 24 , ya que, en palabras de Polo: "uno no se equivoca queriendo, aunque algún antecedente voluntario puede hacerme responsable del error. Pero sí se puede querer mentir; más aún: si no se quiere mentir, no se miente en sentido estricto. Ahí reside, como dirían los moralistas, la malicia de la mentira. La tesis es muy sencilla: la mentira no está nunca justificada y no sólo por consideraciones de tipo moral individual, sino porque desintegra la organización; es el gran corrosivo de la vida social" (2019, p.385). En efecto, "su constitutivo material es el enunciado falso (en esto coincide con el error); pero a ello se añade su carácter voluntario, que es su constitutivo formal (querer que el lenguaje no se adecúe con la verdad). Un tercer constitutivo consecuente o final es intentar engañar para obtener algún provecho" (Polo, 2019, p.385), algún interés práctico. La mentira es siempre pecado, es decir, ninguna mentira es, como algunas personas suelen decir, 'piadosa'. En esto acierta más Víctor Hugo, cuando escribe que "la mentira es lo absoluto del mal. Mentir poco no es posible; el que miente, miente con toda la extensión de la mentira; la mentira es, precisamente, la forma del demonio" (2004, p.141).

Los motivos de mentir son siempre la consecución de bienes útiles, pues si la mentira va contra la verdad, y ésta no tiene sustituto útil, se busca la utilidad. Afirma Polo: "No se miente porque sí (no hay una tendencia natural a la mentira), sino porque se cree que es más ventajoso que decir la verdad" (2019, p. 362). Pero buscando lo útil, quien miente se perjudica a sí mismo porque pierde la verdad, en primer lugar la propia, la personal, el propio sentido, que no es poca pérdida. En efecto, al pactar por dentro con la mentira uno es menos persona que antes, porque verdad y ser coinciden y el 'acto de ser' en el hombre es la 'persona'. Por tanto, la peor pérdida es la trascendental o del acto de ser, el cual, mientras se vive, no se pierde enteramente, pero con la mentira decrece.

La siguiente pérdida que causa la mentira es de orden manifestativo, ético, es decir, de la 'esencia del hombre'. Para Polo: "La mentira afecta directamente a la coherencia del orden social. Aunque mentir vaya seguido de alguna ventaja particular, el balance global de la mentira es negativo porque afecta a las mismas bases de la posibilidad del valor añadido... La mentira afecta a la organización, porque mina la confianza, y sin confianza no hay organización” (2019, p. 386). ¿Cuál es la razón de esto? Que la mentira es la carcoma del lenguaje: En palabras de Polo:

La mentira destruye la organización, porque la organización se basa en la comunicación y la mentira la anula. Si el conectivo social es el lenguaje, corromper el lenguaje es disolvente. Sin ese conectivo es imposible que la división del trabajo se corresponda con la unión de esfuerzos, esto es, perseguir un fin, unos objetivos comunes"(2019, p. 387). ${ }^{25}$

24 Polo, p. 140. Baste recordar que según san Juan, Jesús llama al diablo «padre de la mentira», y que la primera tentación consistió en una mentira acerca de lo que Dios había entregado y prohibido al hombre. Por eso Tomás de Aquino afirma que el pecado original es un pecado de ciencia".

25. A lo que allí mismo ańade: "La mentira mata el diálogo porque es una forma de incomunicación. El objetivo del diálogo es alcanzar contenidos cognoscitivos que todos acepten. Llamaremos a este objetivo el acuerdo por convencimiento. Si la mentira interviene o se sospecha, el diálogo logra, a lo sumo, un pacto entre intereses contrapuestos en el que las partes ceden hasta cierto punto lo que consideran verdadero para evitar la ruptura o para establecer un modus vivendi". (2019, p. 387). 
A este tipo de pactos se dedican actualmente los partidos políticos. Es claro que el que se acostumbra a mentir pierde la confianza de los demás, no solo de los del partido opuesto, sino también de los del propio $^{26}$, de sus colegas y de sus compañeros de 'aventuras' (no hay ladrón que confíe plenamente en su 'socio'). De aquí surge lo que se puede llamar diálogo de sordos, de pasotas o cínicos, es decir, la falta de comunicación.

Si la sociedad se basa en la veracidad comunicativa, "una sociedad basada en la mentira se destruye; los gobernantes que mienten ejercen acciones despóticas" (Polo, 2018, p.312), pues tratan a los demás como si fueran cosas para manipular. Es claro que la colaboración es imposible cuando se miente. Ya lo dijo Polo:

Lo malo de la mentira es la incomunicación que introduce. Con otras palabras, hay que retraer la mentira a la falta de capacidad comunicativa. Guardarse las cosas para uno mismo no es en principio bueno. Aunque, como hemos indicado, en algún momento convenga callar, no puede ser una actitud permanente, porque equivale a un juego de suma cero, y dentro de una institución ese juego conduce a que todos pierdan" (2018, p.366). ${ }^{27}$

Si la mentira implica falta de coexistencia social, es indicio manifestativo de despersonalización interior, puesto que la persona es apertura, relación. Se nota enseguida que lo que está detrás de esta despersonalización es la soberbia, la cual es aislante. El estar centrado en uno mismo se manifiesta, en la práctica, en egoísmo, en buscar los propios intereses.

¿Cómo combatir las mentiras externas? Manifestándolas, poniéndolas al descubierto. También se puede indicar intentando hacerle ver que es soberbio, que mantiene tácita o, más o menos abiertamente, que él es superior a quienes se opone y, por tanto, que pretende más derechos que los demás, lo cual es egoísmo. Si acepta esa advertencia y cambia de actitud, mejor para él; de lo contrario, va camino de la despersonalización, que es lo peor que puede acaecerle.

c) Silencio. Si el hombre no fuera racional, no tendría por qué hablar, porque los hábitos adquiridos de la razón son los que posibilitan el lenguaje (Polo, 2015, pp. 213ss). Por tanto, no hablar es manifestación de que se conoce, o bien infraracional, o bien supraracional. Un ejemplo del primer caso Polo lo pone en el budismo, porque es la actitud de quien pretende quedarse en el nivel más inferior de la inteligencia, un conocer sin contenidos: "lo que Buda pretende es el silencio lingüístico"28. Además, si bien se mira, no

26 Por ejemplo, afirma Polo: "sostener que un hombre de empresa puede mentir hacia el exterior, pero no en el interior de la organización, es una dualidad inadmisible: solamente podría aceptarse si, al mentir, el hombre no se volviera mentiroso. Ahora bien, ocurre que no hay sólo mentira: hay mentirosos; ser mentiroso es una consecuencia inexorable de mentir. Pero es razonable desconfiar del mentiros" (2019, p. 387).

27 Polo, 2019, p. 366. A título de ejemplo se puede recordar que el diablo es el padre de la mentira. Por eso Polo decía que 'en el infierno solo se habla de yo', o si se quiere, solo se conjugan los pronombres 'personales', los cuales no deberían llamarse así, porque no responden a la persona, sino al 'yo'. En el infierno se pierde enteramente el ser personal; si permaneciera el 'ser personal', no se podría hablar solo del 'yo'.

28 Polo, 2015, pp. 216. En otro lugar añade: "la negación de la teoría en Dios es la clave misma del budismo; por eso suelo decir que Buda es el ateísmo lógico. Buda no dice que Dios no exista, sino que Dios es puro silencio, pura inactividad, incluso intelectual". Polo, La esencia del hombre, p. 55. 
es solo un asunto racional, sino ético, porque es propio del hombre aportar, y es claro que hablar es dar (al menos, dar conversación). Por eso, la raíz de donde nace en nosotros la ética, el hábito innato de la sindéresis, impele a hablar, actividad que solo hay que omitirla cuando no conviene respeto a la fama de las personas ${ }^{29}$ o por temas que son de secreto natural o profesional, los cuales no deben saber los demás. Dice Polo: "vivir no diciendo lo que no conviene decir constituye también un arte y, en el fondo, es una virtud porque no conviene ser indiscreto, y hay secretos naturales, o secretos de oficio" (2019, p. 362) ${ }^{30}$.

Decíamos que, aunque pueda parecer que a corto plazo se gane mintiendo, a largo plazo se pierde, porque nadie quiere volver a hacer negocios con un embustero. Ahora se debe añadir que, aunque parezca ventajoso en algunos casos el silencio, generalmente no lo es, por lo que "se debe sentar con energía un principio universal: en principio es mejor hablar que callarse... es más humano hablar que callarse. Contribuye más a la vida social, siempre que no sea hablar de trivialidades o chismorrerías. Aporta más al hombre hablar que el silencio... Más todavía: el hombre está hecho para comunicarse, no para denegar la comunicación. Existe una obligación moral, derivada del destino del hombre a la verdad, a no reservarse lo que se sabe, y al que corresponde un derecho a ser escuchado. Asimismo, reservarse la capacidad de escuchar, o limitarla a unos pocos, es un prejuicio individualista o elitista del que conviene librarse" (2019, p. 364-5). De todos se puede aprender, aunque es obvio que de unos más que de otros. En el plano trascendental, de quienes saben más acerca del 'acto de ser', personal abierto a la trascendencia divina; en el plano manifestativo, de los más virtuosos, es decir, de quienes saben más acerca de la 'esencia del hombre'. Al parecer, este no es el caso de la mayor parte de los medios de comunicación, de los representantes políticos, o famosos de la sociedad.

El silencio está justificado para hablar con Dios, porque Él 'habla' en nuestra intimidad, sin ruido de palabras $^{31}$. La intimidad humana es silenciosa; busca a Dios sin palabras ${ }^{32}$. En los demás casos el silencio tiene menor justificación. No la tiene, en ningún caso, el ruido deshumanizante en gritos y estruendos que no son músicas. El fin de hablar y de la música es que sean escuchados. Pero no todo lo que se llama

29 "En principio la sindéresis dice: habla, pero la conciencia puede decir: en este caso es mejor guardar silencio. Pero el dictamen es incompleto, porque en principio (no digo en general) es mejor hablar que no hablar. Eso lo descubre el intelecto del ser humano. Pero es un principio. Y tan es un principio que el problema de cómo actúo hay que resolverlo con la razón. Con todo, la conciencia no se aísla de la sindéresis; hay conciencia moral porque hay conocimiento del principio. Si no, no tendría sentido plantearse si debo hacer esto o lo otro". (Polo 2018, p. 283).

30 "A veces... se guarda silencio. Como afirman los banqueros suizos, la palabra es plata, pero el silencio es oro. En el caso de la banca suiza está claro, pero también en otros negocios; por ejemplo en las relaciones con los competidores, el silencio vale mucho... La idea de patente, de copyright, comporta no decir de qué se trata, sorprender o no dar al otro tiempo para que imite, buscar el monopolio. El secreto parece asegurar muchas veces lo que se suele llamar el monopolio natural, entendiendo por ello el hecho de que con una buena idea aplicada por primera vez, se obtiene un producto con mejores prestaciones (precios más bajos, etc.) que otros que ya están en el mercado, es decir, se logra una ventaja en virtud de la cual el nuevo producto será preferido a los demás. Naturalmente, los competidores intentan reducir su desventaja buscando algo análogo para vencer el monopolio inicial” (2019, p. 362).

31 "La co-existencia es silenciosa, pero la persona humana no se conforma con el silencio, sino que busca y se manifiesta. La manifestación es la victoria potencial, o esencial, sobre el silencio". (Polo, 2015., p. 282, nota 5). A este propósito Kowalska ha dicho que "el silencio es un lenguaje tan poderoso que alcanza el trono del Dios viviente. El silencio es su lenguaje, aunque misterioso, pero poderoso y vivo" (1996, p. 351).

32 "La persona es silenciosa porque busca". (Polo, 2015., p. 507, nota 271). 
hablar lo es; ni tampoco todo lo que se llama música ${ }^{33}$, ni toda estridencia debe ser escuchada. Del mismo modo que 'a palabras necias, oídos sordos', y con cierta 'música, a otra parte', con algunos ruidos hay que proceder sabiendo que 'aquel es tu amigo, el que te quita el ruido'.

d) Doblez o hipocresía. La doblez es "otra forma de atentar contra la veracidad. Es faltar a la palabra dada... La doblez niega con los hechos lo que dice la palabra" (Polo, 2015., p. 392). Este defecto puede afectar al hombre porque el ser humano no es simple (como el divino), sino compuesto por diversas dimensiones distintas jerárquicamente entre sí. Todas ellas conforman dualidades, es decir, se unen formando pares de modo que la inferior sirve a la superior y ésta favorece a aquélla. Lo conveniente es que las inferiores manifiesten el ser de la superior, la personal, pero también pueden no hacerlo. De hecho, "la hipocresía, el disimulo, la mentira, son formas derivadas y decaídas de dualidad" (Polo, 2015, p. 189 $)^{34}$. La hipocresía manifiesta la incoherencia entre las dimensiones humanas en hechos y palabras; el disimulo, en gestos corpóreos; y la mentira, en palabras. De modo que la peor de las tres es la primera porque miente con palabras y obras.

Manifestaciones de este vicio son muchas. Así, la gente que promete y no cumple carece de compromiso, y a quien no cumple los pactos se le llama traidor, pues pacta sunt servanda. La doblez es la mentira en los hechos. Según Polo (2019): "la doblez práctica es la peor forma de mentira... dejar de hacer lo pactado se ha de prevenir con reglamentos, porque destruye la organización del trabajo... Sin duda, quien no cumple su palabra es una rémora, un peso muerto en la organización" ${ }^{35}$. Ordinariamente llamamos hipocresía a la doblez, y ponemos como prototipos de ella a los fariseos del tiempo de Cristo, porque vivían una doble vida: una aparentemente religiosa y legal, de cara afuera, y otra pervertida, en privado. Pero, por encima de eso, negaban la Verdad suprema, la revelada. Por eso, Cristo los llamó 'sepulcros blanqueados', porque por fuera parecín bonitos y por dentro estabn llenos de corrupción. Tales personajes se parecen a los clérigos protestantes daneses que criticó Kierkegaard en el s. XIX, o a los alemanes que denigró Nietzsche en esa misma centuria, y también a muchos eclesiásticos católicos inculpados en el s. XXI por el cardenal Sarah. Que este vicio está reńido con la virtud de la veracidad es patente, porque, como diría Polo: "la sinceridad es hablar sin rodeos y con confianza, así como disentir sin hipocresía y abrir libremente el propio interior: esto se llama franqueza" (2015, p. 475). Pero este defecto no solo corroe la vida eclesiástica, sino que también "la vida social está teñida de hipocresía; el miedoso y el embustero, socialmente, es hipócrita" (Polo, 2019, p. 334). La sociedad burguesa de los ss. XIX y XX ha estado llena de convencionalismos sociales, que como careta ocultaban el verdadero rosto de mucha gente. Pero la sociedad postmoderna, si bien 'pasa' de aquellas 'formas' antaño vigentes, no 'pasa' de las actuales. Es obvio que esa vida doble de muchos causa un clima generalizado de desconfianza. De lo contrario no tendría razón de ser la crisis humanística por la que atravesamos.

33 "En el cielo tiene que haber música, decía Platón. Por eso todavía se habla de la música celestial. Hay una profunda intuición ahí, una profunda comprensión. Estar eternamente silencioso sería ateo”. (Polo, 2015., p. 155).

34 En otro lugar ańade: "Cuerpo y alma, voluntad e inteligencia, intervalo interno y medio externo, sujeto y objeto, hecho y límite, etc., son modos de apreciar esta dualidad. En ella se basa también la doblez (la hipocresía, el disimulo, el fingimiento, el solapamiento). La doblez presupone la dualidad y sólo así es posible”. (2019, pp. 102-103).

35 A lo que agrega: “¿Qué pasa cuando una piedra es llevada entre dos, y uno no cumple su cometido, sino que descarga el peso en el otro? Es obvio que ese otro no querrá seguir trabajando con el falsificador de la colaboración” (p. 393). 


\section{Ventajas de la sinceridad}

Sin pretensión de exhaustividad, atendamos ahora a algunas ventajas que, según L. Polo, se derivan de ser sinceros y veraces, en vez de mentir con palabras, gestos o hechos.

a) La alegría. La primera ventaja que se puede resaltar de esta virtud es que el sincero es alegre, mientras que el hipócrita es internamente triste, aunque se fuerce fingiendo contento. Esto es así porque el sincero busca la verdad; en palabras de Polo: "la verdad es alegre, ya que es preferible a cualquier otro objetivo vital, y reclama sinceridad de vida, búsqueda. Conviene empezar de una buena vez sin prisas; importa no ser escéptico, no renunciar a la tarea de buscarla y servirla, por más que parezca utópica o inalcanzable. Buscar la verdad lleva consigo ser fiel a ella, no admitir la mentira en uno mismo" (2015, p.28). Esto por lo que toca a la razón cuyo tema es la verdad.

En lo que respecta a la voluntad, Polo dice:

La sinceridad de los actos voluntarios reside en la completa exclusión de la astucia. La astucia se suele entender como uno de los vicios opuestos a la virtud de la prudencia. Aquí empleo la palabra en su sentido más elemental, es decir, como el desfigurar los bienes conocidos por la razón práctica al modo como, según la fábula, la zorra declaró verdes las uvas que apetecía al no poder alcanzarlas. (Polo, 2015, p. 440).

La voluntad torcida está mustia. Si la voluntad es recta, está inicialmente abierta a muchos bienes mediales, a pluralidad de alternativas, no aquella que se ha encaprichado injustificadamente. Luego, la voluntad sigue a la posibilidad que la razón ha destacado como la mejor, y más tarde, cuando la razón lo decreta, pone manos a la obra para su realización. Eso por lo que se refiere a los bienes mediales. Pero si la voluntad se refiere a las personas, la voluntad es recta cuando persigue en ellas una amistad sincera, puesto que esta es la virtud superior de esta potencia ${ }^{36}$. Precisamente por esto, entre amigos, "el diálogo tiene que ser sincero" (Polo, 2019, p. 180). En efecto, la sinceridad entre los amigos es como la de los niños pequeños: sin malicia. Y así conviene que sea la amistad entre los matrimonios, entre padres e hijos y entre los colegas de estudio o trabajo en universidades y empresas.

¿Quién es, de entre los que estudian o trabajan, el que más fomenta una adhesión sincera? Quien tienen grandes ideales a largo plazo. Cabe hablar de una ambición positiva y de otra negativa. La primera persigue objetivos comunes buenos y es convocante; la segunda persigue solo bienes privados y es aislante. Eso no equivale a decir que entre colegas o entre quienes conviven no medien intercambios de pareceres, es decir, discusiones, pero estas tienen que ser sinceras. Es decir, que tengan como norte la verdad; lo contrario, más que no llevar a ninguna parte, deshumaniza.

b) La audacia. Otra ventaja positiva de la sinceridad es la ausencia de miedos. Estos llevan a no hablar con trasparencia, porque el miedo inhibe el lenguaje, mientras que la sinceridad lo fomenta. En opinión de Polo:, "si el directivo se deja dominar por el miedo, se anula. Si el dirigido entra también en la dramática espiral del miedo, es imposible dirigirlo. Dicho de otra manera, a una persona atemorizada

36 "Si las cosas pequeñas tienen un gran valor ascético, mayor valor tiene todavía el de la amistad sincera”. (Polo, 2018, p. 177). 
no se le puede hacer entender ningún proceso activo autocontrolado. Aquí podemos apelar a lo que dice Wittgenstein acerca del terror: el terror es la suspensión, la paralización del discurso. Para Wittgenstein, que es un filósofo del lenguaje, el terror da lugar justamente a la falta de articulación lingüística: no cabe 'logos' en el sentido griego de la palabra. La razón no gobierna la conducta, y esta última desaparece” (2019, p. 361). Ya se ha insistido en que sin lenguaje veritativo no cabe comunicación propiamente humana y, sin esta, no cabe cohesión social ${ }^{37}$.

Cuesta decir la verdad, supone esfuerzo. Decirla siempre conlleva sacrificio. Pero al proferirla se gana, más que en fortaleza, en audacia. Por eso, es buena esta comparación literaria de Víctor Hugo: "Cuando por casualidad se encuentran un anciano sacerdote y un viejo militar, si ambos son sinceros y buenos, nadie se comprende ni se amalgama más fácilmente porque en el fondo son una misma cosa: el uno se sacrifica por la patria de aquí abajo, y el otro por la patria de allá arriba: no hay más diferencia” (2004).

c) El incremento del bien común y subordinación de este al sentido personal. Dice Polo: "El diálogo se compone de una serie de enunciados que se hacen comunes; comunicar es poner en común; poner en común es mejor que la reserva, porque un valor poseído de modo exclusivo, un valor que uno solo tiene, aumenta cuando es patrimonio común (de acuerdo con las posibilidades de cada uno) e intensifica su dinámica de crecimiento" (2015, p.366). Sin diálogo, difícilmente se incrementa la virtud, que es el bien común superior al que deben tender los ciudadanos y las instituciones sociales. Polo continúa: "La dimensión lingüística de la sociedad es clarísima; por eso, siempre que no se trate de fruslerías, es mejor hablar que callarse. De ello depende la cohesión de la sociedad. Y cuando se trata de una institución, de un grupo social más reducido, como son las empresas, o la familia, la comunicación ad intra es imprescindible" (Polo, 2015, p.366) ${ }^{38}$. De hecho, las mejores empresas hoy son aquellas en las que hay una mejor comunicación entre sus integrantes. En efecto, si los demás saben más, pueden crecer más, y si crecen más, apremian a los demás a que se desarrollen, evitan el estancamiento. A esto obedece ese axioma práctico que formuló Polo: 'todo éxito es prematuro'. También, las familias más unidas son las mejor comunicadas, las más dialogantes. Téngase en cuenta que lo más relevante del diálogo es saber escuchar y comprender, no hablar, porque el fin del hablar es ser escuchado y, sobre todo, entendido.

Arriba se ha añadido al sustantivo 'lenguaje' el adjetivo 'veritativo', o sea, según verdad. Las verdades que se manifiestan en el lenguaje son de índole universal, porque las palabras se refieren a los pensamientos, y estos son universales. Por tanto, el hablar con veracidad implica que, quien así habla, subordina las verdades universales a la verdad personal e irrepetible que cada quien es. Porque el habla-como la músicatiene como fin el ser escuchado. lo cual, bien mirado, indica que este modo de hablar advierte la dignidad personal de cada quién. Por eso, los pensadores medievales entendían a la veracidad como una parte de la

37 Dice Polo: "La capacidad de hablar es un requisito de su sociabilidad". Ibid., p. 370. En otro lugar insiste: "La virtud de la veracidad, si no existe, anula la comunicación. La veracidad afecta radicalmente a la sociedad: la sociedad es imposible sin ella. Sin verdad es imposible convivir. Sin intercambio de verdades es imposible educar a nadie. Sin intercambio de verdades no hay organización, ni en el nivel directivo ni en el ejecutivo. Si la gente hace chanchullos, no cumple sus pactos y no es fiel a su palabra, ¿quién se fía de ellos? La confianza se rompe”. (2015, p. 440).

38 Y más adelante: "La veracidad conlleva aumento de información, comunicación, capacitación”. (p. 450). 
justicia $^{39}$, pues si esta se describe como 'dar a cada uno lo suyo', lo que cada uno requiere es que se le diga la verdad, porque la persona es una verdad superior.

d) El enamoramiento, porque, como dice Polo: "encontrarse con la verdad, enamorarse de ella, es lo más propio de un ser humano". ${ }^{40}$ Como el hombre es un ser social, aunque el encuentro con la verdad es experiencial, sapiencial, la mayor parte de las veces se descubre la verdad por medio del diálogo. Es claro que no cabe enamoramiento sin naturalidad (un amor forzado está condenado al fracaso); quien no se comporta de acuerdo con lo que dice, no es veraz y no se enamora de verdad.

\section{Referencias}

Grossman, V. (2007). Vida y destino. Círculo de Lectores.

Hugo, V. (2004). Los miserables. Aguilar.

Jaspers, K. (2005). Kierkegaard hoy. Sartre, J. P., et al (Eds.), Kierkegaard vivo. Una reconsideración.: Encuentro.

Kierkegaard, S. (1982). Diario (1853):: Morcelliana

Kowalska, M.F. (1996). Diario, La Divina Misericordia en mi alma. Donnelley \& Sons Company.

Millán-Puelles, A. (1997). El interés por la verdad. Rialp.

Polo, L. (2015). Antropología trascendental, Obras Completas. Eunsa.

Polo, L. (2015). Evidencia y realidad en Descartes, Obras Completas. Eunsa.

Polo, L. (2015). Filosofia y economía, Obras Completas. Eunsa.

Polo, L. (2015). Introducción a la filosofía, Obras Completas. Eunsa.

Polo, L. (2015). La originalidad de la concepción cristiana de la existencia, Obras Completas. Eunsa.

Polo, L. (2015). La persona humana y su crecimiento, Obras Completas. Eunsa.

Polo, L. (2015). Nominalismo, idealismo y realismo, Obras Completas. Eunsa.

Polo, L. (2015). Persona y libertad, Obras Completas. Eunsa.

Polo, L. (2015). Presente y futuro del hombre, Obras Completas. Eunsa.

Polo, L. (2015a). Curso de teoría del conocimiento, Obras Completas. Eunsa.

Polo, L. (2015b). Curso de teoría del conocimiento. Eunsa.

Polo, L. (2015c). Estudios de filosofia moderna y contemporánea, Obras Completas. Eunsa.

Polo, L. (2018). Curso de psicología general, Obras Completas. Eunsa

39 "El que no es veraz no puede ser justo, y sin justicia y sin veracidad no puede haber confianza”. (Polo, 2015, p. 428). 40 ??????? 
Polo, L. (2018). Ética: hacia una versión moderna de los temas clásicos, Obras Completas. Eunsa.

Polo, L. (2018). Lecciones de ética, Obras Completas. Eunsa.

Polo, L. (2018). Nietzsche como pensador de dualidades, Obras Completas. Eunsa.

Polo, L. (2019). Antropología de la acción directiva, Obras Completas. Eunsa.

Polo, L. (2019). Ayudar a crecer. Eunsa.

Polo, L. (2019). El hombre en la historia. Eunsa.

Sellés, J. F. (1999). La virtud de la prudencia según Tomás de Aquino. Cuadernos de Anuario Filosófico, 90.

Sellés, J. F. (1999). Razón teórica y razón práctica según Tomás de Aquino. Cuadernos de Anuario Filosófico, 101.

Sellés, J. F. (2008). Los hábitos intelectuales según Tomás de Aquino. Eunsa.

Sellés, J. F. (2012). Sin verdad no cabe verdadera amistad. Miscelánea Poliana, 39, 9-14.

Sellés, J. F. (2013). Los tres agentes del cambio en la sociedad civil: familia, universidad y empresa. Eiunsa.

Tomás de Aquino. (2010) Summa Theologiae. Madrid: Biblioteca de autores cristianos.

Tomás de Aquino., \& Mendoza, C. A. L. (2001). Comentario a la Ética a Nicómaco de Aristóteles. Eunsa 